\title{
Melatonin inhibits the up-regulation of N-type calcium channel in neuropathic pain by activating the MT2 receptor in rats
}

\author{
JUN-JIE TIAN ${ }^{1}$, YING-YING ZHANG ${ }^{1}$, ZHAO-YANG TAN ${ }^{1}$, NAN CAO ${ }^{1}$, ZU-WEI \\ $\mathrm{QU}^{2}$, XUE-ER YANG ${ }^{1}$, LI-CANG ZHU ${ }^{3}, \mathrm{KE}-\mathrm{TAO} \mathrm{MA}^{1}, \mathrm{Li} \mathrm{LI}^{4}$, and JUN-QIANG SI ${ }^{1}$
}

\author{
${ }^{1}$ Shihezi University School of Medicine \\ ${ }^{2}$ Shihezi University \\ ${ }^{3} \mathrm{NHC}$ Key Laboratory of Prevention and Treatment of Central Asia High Incidence \\ Diseases (First Affiliated Hospital, School of Medicine, Shihezi University) \\ ${ }^{4}$ Medical School of Jiaxing College
}

December 13, 2021

\begin{abstract}
The aim of the study was to clarify the effect of melatonin on neuropathic pain by N-type calcium channel (Cav2.2) inhibition in dorsal root ganglion (DRG) neurons after spared nerve injury (SNI) surgery. Immunofluorescence was used to identify the co-expression of Cav2.2 and the MT2 receptor and detect the changes in Cav2.2 expression in DRG neurons. Western-blot was also performed to detect the expression of Cav2.2 in DRG neurons. The action potential and current of Cav2.2 channels in DRG neurons were detected using whole-cell patch clamp analysis. Behavioral studies were conducted using thermal stimulation and acetone after melatonin was injected intraperitoneally. The results revealed that Cav2.2 and the MT2 receptor were coexpressed in medium and small sized DRG neurons, and the intensity of Cav2.2 increased after SNI. Injection of melatonin activated the MT2 receptor and relieved nociceptive pain through decreased the Cav2.2 expression and current in DRG neurons. Melatonin can significantly decrease the increase in Cav2.2 current density and excitability after SNI. In addition, the Cav2.2 activation curve shifted to the left after SNI, but there was no change in inactivation. $10 \mu \mathrm{M}$ melatonin significantly inhibited the excitability of DRG neurons and Cav2.2 current, the inactivation curve of Cav2.2 current shifted significantly to the left. However, the MT2 receptor antagonist 4-P-PDOT reversed the inhibition of melatonin on Cav2.2 current. We conclude that melatonin inhibits the increased Cav2.2 expression and current; on the other hand, it reduces the excitability of DRG neurons after SNI surgery via the MT2 receptor pathway.
\end{abstract}

\section{Introduction}

For decades, one of the most popular ideas in neuropathic pain literature has been that neuropathic pain, as defined recently by the International Association for the Study of Pain in 2011, is pain caused by somatic sensory nervous system injury or disease [1]. In the past epidemiological studies have shown that the incidence of chronic pain in the general population is $20 \%$ to $25 \%$ [4], of which the prevalence of neuropathic pain may be as high as $7 \%$ to $8 \%[2,3]$, accounting for about one fifth of patients with chronic pain. And ion channels play a huge role in neuropathic pain. There are studies that show that the electrophysiological basis of neuropathic pain is usually the increased expression of $\mathrm{Na}+$ channel and voltage-gated $\mathrm{Ca}^{2+}$ channel in the injured nerve cell membrane, which changes the normal physiological activities of neurons and aggravates the peripheral stimulation response to non noxious or minor injury. Among them voltage-gated calcium channels are the main channels involved in depolarization-mediated calcium entry into neurons. The calcium channel family consists of many different channel subtypes and can be broadly divided into two groups based on their voltage dependence of activation: low voltage activation channels and high voltage activation channels 
$[5,6]$. N-type voltage-dependent calcium channels (N-VDCCs) are high voltage activated channels that are closely related to pain regulation and are distributed in the neural pathway of nociceptive information transmission. After activation, they trigger the release of pain-related neurotransmitters from synaptic vesicles by causing calcium influx and pain conduction. Mainly,N-type voltage-dependent calcium channels (N-VDCCs) are high voltage activated channels closely related to pain regulation, which are distributed in nerve cells of nociceptive information transmission pathway. After these channels are activated, they cause calcium influx into neurons, trigger synaptic vesicles to release pain related neurotransmitters, and produce and transmit pain. In the dorsal root ganglia (DRG) and spinal dorsal horn pain-transmitting neurons, N-VDCC current accounts for $60 \%$ to $70 \%$ of that of all high-voltage activated calcium channels (L-, N.-, P-, Q-, and R-type) [7]. The N-VDCC has long been considered as a target for the development of analgesic drugs. Many drugs in clinical use, such as pregabalin, gabapentin, and ziconotide, inhibit pain by acting on N-type calcium channels [8]. However, their use is likely to be associated with side effects, such as drug withdrawal syndrome, auditory hallucinations, delusions, euphoria, ataxia, psychosis, and paresthesia [9]. So, the development of potent yet less addictive analgesics remains a challenge and has always been one of the hot spots in the field of drug research and development.

With the deepening of research, N-acetyl-5-methoxytryptamine (melatonin) gradually became known. Melatonin is a hormone secreted by the pineal gland at an increased level at night and plays a role in regulating the sleep-wake cycle, changes during puberty, and seasonal adaptation [10]. Melatonin has anxiolytic, antioxidant, anti-injury, anti-depressive, anti-anorexia, anti-tumor, anti-inflammatory, neuroprotective effects, lowers blood pressure in retinal blood vessels, and regulates exercise activity and pain [11]. Recently, more and more studies have focused on the multiple functions of melatonin and its receptors subtypes [12]. Altiparmak et al. showed that rapid melatonin supplementation can significantly improve the daytime sleepiness side effects of gabapentin [13]. Melatonin may change cytosolic calcium ion levels and lead to tumor cell apoptosis [14]. Furthermore, a study by Zhu et al. showed that melatonin protects cardiac microvascular endothelial cells from oxidative stress damage by activating MAPK/ERK signaling pathway [15]. However, the effect of melatonin on N-type calcium channels in DRG neurons is rarely studied.

Establishing an appropriate animal model of neuropathic pain can provide a theoretical and practical scientific basis for further exploration of the pathogenesis of neuropathic pain and the search for more effective drugs and treatments. The Chronic constriction injury (CCI) [16], spared nerve injury (SNI) [17], spinal nerve ligation (SNL) [18], and partial sciatic nerve ligation (PSNL) [19] models are typical surgical animal models used for this purpose. Among them, the SNI model has good mechanical pain and thermal allodynia, and its duration is longer than that of other models of neuropathic pain. Because it is the closest model to clinical neuropathic pain, researchers often choose SNI model to study pain.

Based on the above reasons, we will use a variety of experimental methods to study the changes of Cav2.2 expression, activation current and neuronal excitability in DRG neurons after standby nerve injury (SNI), and the effect of melatonin on these changes. MT2 agonist 4-p-pdot (n - [(2S, 4R) - 4-phenyl-1,2,3,4-tetralin2-yl] Propionamide) was used to prove that the effect of melatonin on Cav2.2 expression and activation current was mediated by MT2 receptor. Our ultimate goal is to clarify whether melatonin is involved in pain modulation by regulating the expression and function of Cav2.2 on DRG neurons through acting on MT2 receptor, so as to confirm whether MT2 receptor can become a new target for the treatment of neuropathic pain.

\section{Materials and Methods}

\subsection{Animals}

All experiments were performed on adult male Sprague-Dawley rats weighting 180-250 g obtained after approval from the Xinjiang Medical University Animal Center (approval no. SCXK Xin2003-0001). In a specific pathogen-free environment with controlled temperature and a 12:12 hours light/dark cycle, five rats were kept in each cage and given ad libitum access to food and water. Animal experiments were conducted with the approval of the Institutional Ethics Review Board at the First Affiliated Hospital of the 
Medical College of Shihezi University and were performed in accordance with the ethical guidelines of the International Pain Research Association's experimental pain survey of conscious animals.

\subsection{Establishment of the SNI model in rats and drug delivery}

The SNI model was established as described previously [17]. Under isoflurane anesthesia (5\% induced anesthesia and $2 \%$ continuous anesthesia), an incision was made into the skin on the outer left thigh of each rat, and the bicep femoris muscle was bluntly separated to expose the sciatic nerve and its three branches: the sural, common peroneal, and tibial nerves. The sciatic nerve was gently separated, the tibial and the common peroneal nerves were tightly ligated using 4-0 silk and sectioned distal to the ligation, and $3 \mathrm{~mm}$ of the distal stumps at this level were removed leaving the sural nerve intact. Subsequently, the muscle and skin were closed. Extreme care was taken to avoid excessive pulling of the nerves during the surgery. In the Sham group, the sciatic nerve was isolated and exposed but not injured. The rats were then kept in a warm environment, and vital signs were monitored until complete recovery from anesthesia. Post-operatively, the rats were provided enhanced nutrition and subjected to single-cage feeding, infection prevention, and a strict 12 hours light/dark cycle.

After recovery, all rats were tested for pain behavior, and only rats exhibiting apparent pain behavior were used for different treatment regimens :1) SNI + Vel group: rats received intraperitoneal (i.p.) injections of $50 \mathrm{ml} / \mathrm{kg}$ vehicle (1\% ethanol in normal saline), SNI + Mel group: rats received i.p. injections of $50 \mathrm{mg} / \mathrm{kg}$ melatonin [20], SNI + Mel + 4PP group: rats received i.p. injections of $50 \mathrm{mg} / \mathrm{kg}$ melatonin and $20 \mathrm{mg} / \mathrm{kg}$ 4-P-PDOT. Drug treatment was given every day for 21 days after SNI surgery.

\subsection{Behavioral tests}

As described in our previous study [21], the threshold responses to painful thermal stimulation of the hind limbs on the surgical side were evaluated 1 day before surgery and $1,3,7,14$, and 21 days after surgery. After the rats had been quiet for more than 15 minutes, 3 tests were performed for each rat every 5 minutes, and the results of the 3 tests were averaged (minimum value of $0.5 \mathrm{sec}$ and maximum value of $20 \mathrm{sec}$ ). Data were expressed as thermal withdrawal latencies.

As described previously [22], using a blunt needle connected to a syringe, a drop of acetone solution was carefully dropped on the sole of the foot without the needle touching the skin, and the duration of paw withdrawal in the $30 \mathrm{sec}$ immediately following acetone application was measured. Cold allodynia measurements were repeated 3 times per day for each animal, and the average was taken. The next stimulus was administered once the animal was quiet. Data were expressed as the time that the paw was lifted (minimal value of $0.5 \mathrm{sec}$ and a maximum of $20 \mathrm{sec}$ ).

\subsection{Reagents and instruments}

The main reagents used in the present study were mouse anti-Cav2.2 antibody (Sc-377489, monoclonal, Santa Cruz, USA), rabbit anti-Cav2.2 antibody (ab5154, monoclonal, CA, USA), rabbit anti-melatonin receptor 1A (MT1) antibody (ab:203038, polyclonal, Abcam, Cambridge, MA, USA) rabbit anti-melatonin receptor 1B (MT2) antibody (ab:203346, polyclonal, Abcam, Cambridge, MA, USA), mouse anti-NF-200 antibody (ab82259, Abcam, Cambridge, MA, USA), mouse anti-CGRP antibody (ab81887, Abcam, Cambridge, MA, USA), isolectin B4 (IB4, Sigma, USA), dimethylsulfoxide (DMSO, Sigma-Aldrich, Merck KGaA), radioimmunoprecipitation assay buffer (RIPA buffer, Thermo Fisher Scientific, Inc., Waltham, MA, USA), phenylmethylsulfonyl fluoride (PMSF, Sigma-Aldrich, Merck KGaA, USA), 4P-P-DOT (SML1189, Sigma-Aldrich, CA, USA), NP118809 (A3666, APExBIO, USA), melatonin (A2842, APExBIO, USA), and isoflurane (RWD Life Science, China).

The equipment used included an automatic thermal radiation stimulator (37370 Plantar Test Apparatus, UGO BASILE S.R.L., Varese, Italy), a patch clamp amplifier (MultiClamp 700B, Axon Instruments, Molecular Devices, LLC, Sunnyvale, CA, USA), a MODEL P-97 Brown Micropipette Puller (Sutter Instrument Company, USA), a biological data acquisition system (Digidata 1550A, Axon Instruments, Molecular Devices, LLC), a micromanipulation instrument (MP-225, Sutter Instrument Company), and an ordinary 
optical microscope (Olympus Corporation, Tokyo, Japan).

\subsection{Isolation and culture of DRG neurons}

DRG neurons were isolated using enzyme digestion as previously described [23]. Firstly, rats were anesthetized using isoflurane and sacrificed by cervical dislocation, and the thoracic and lumbar segments of the vertebral column were surgically removed. Next, the segmental $\mathrm{L}_{4}-\mathrm{L}_{6} \mathrm{DRG}$ was removed quickly, the redundant nerve fibers and connective tissues were amputated, and the DRG neurons were cut into pieces using sclerotic scissors in extracellular fluid $\left(150 \mathrm{mM} \mathrm{NaCl}, 5 \mathrm{mM} \mathrm{KCl}, 2.5 \mathrm{mM} \mathrm{CaCl} 2,1 \mathrm{mM} \mathrm{MgCl} \mathrm{H}_{2} \cdot \mathrm{H}_{2} \mathrm{O}, 10\right.$ $\mathrm{mM}$ HEPES, $10 \mathrm{mM}$ D-glucose; $\mathrm{pH}$ was adjusted to 7.4 using $\mathrm{NaOH}$ ) at a low temperature (on a mixture of ice and water). Next, the ganglia were gently dissociated using a fire-polished Pasteur pipette and treatment with digestive enzymes (pancreatic protease, $0.12 \mathrm{mg} / \mathrm{ml}$ and collagenase, $0.1 \mathrm{mg} / \mathrm{ml}$ ) at $37^{\circ} \mathrm{C}$. Digestion was terminated using DMEM containing 10\% fetal bovine serum, and the DRG neuron cell suspension obtained after enzymatic and mechanical dissociation was plated on poly-d-lysine $(0.5 \mathrm{mg} / \mathrm{ml}$, Sigma, USA) pretreated $35 \mathrm{~mm}$ cell culture dishes specially designed for electrophysiological recording. After the cells had adhered, the medium was replaced with extracellular fluid pretreated with $\mathrm{O}_{2}$, and electrophysiological experiments were then performed.

\subsection{Immunofluorescence and}

immunohistochemistry experiments

As described previously [21], rats were deeply anesthetized using isoflurane and perfused through the aorta with normal saline followed by $4 \%$ paraformaldehyde in $0.1 \mathrm{M}$ phosphate buffer for 10 minutes. After perfusion, $\mathrm{L}_{4}-\mathrm{L}_{6}$ DRG neurons were removed and post-fixed in the same fixative for 3 hours and then in $30 \%$ sucrose (in $0.1 \mathrm{M}$ PBS) for 24 hours. DRG neuron sections ( $5 \mu \mathrm{m}$ thickness) were prepared using a freezing microtome, mounted on gelatin-coated slides, and air-dried. Sections were washed and incubated in blocking buffer (5\% BSA in PBS with Tween-20) for 1 hour at 25, washed with $0.01 \mathrm{M}$ PBS, and incubated with primary antibody in a wet box at $4{ }^{\circ} \mathrm{C}$ overnight. Next, secondary antibodies were used for incubation at room temperature for 120 minutes.

For Cav2.2 and MT2 co-expression experiments, sections were incubated with anti-Cav2.2 (mouse monoclonal, SANTA CRUZ, USA, 1:100) and anti-MT2 (rabbit polyclonal, Abcam, USA, 1:100). In order to prove the expression on DRG neuron s, we used primary antibody anti-Cav2.2 (rabbit monoclonal, Abcam, 1:100) and primary antibody anti-MT2 (rabbit polyclonal, Abcam, 1:100) and anti-neurofilament-200 (NF-200, mouse monoclonal; a marker for myelinated A-fibers; 1:200)/anti-calcitonin gene related peptide (CGRP; mouse monoclonal; a marker of peptidergic C-type neurons; 1:200). Then, secondary antibodies (TRITC/FITC, 1:200) were used at 25 for 120 minutes. For the relevant experiments, FITC conjugated IB4 (a marker for nonpeptidergic C-type neurons; $20 \mathrm{mg} / \mathrm{ml}$; Sigma, St. Louis, USA) was used for processing tissue sections during incubation with secondary antibodies. The sections were rinsed with $0.01 \mathrm{M} \mathrm{PBS}$ three times, mounted on gelatin coated slides, and air-dried. Sections were examined using a confocal laser scanning microscope (LSM710, Carl Zeiss AG, Oberkochen, Germany). Immunofluorescence quantifications for all target proteins were performed by measuring the mean absorbance following laser confocal microscopy using the Image $\mathrm{J}$ Launcher software (National Institutes of Health, USA).

It's similar to immunofluorescence [21, 40], for ABC-DAB staining, sections were incubated with the primary antibody at $4 \mathrm{degC}$ overnight (Antibodies were prepared at the ratio of 1:100 with 0.01 M PBS). Subsequently, on the next day, wash the primary antibody and add the secondary antibody, incubate at 37degC for 1 hour, add DAB for color development, and rinse off with distilled water immediately after the positive part of the antibody labeled with the specimen develops, then counter-stain with hematoxylin for 3 minutes, and wash with distilled water three times, with acid alcohol differentiation for 6-7 seconds, with distilled water for 3 times, then distilled water to blue for 3 minutes, then dehydrated in graded ethanol, dried and mounted with neutral gum. Randomly select 6 samples in each group, and randomly select 5 fields of view in each sample to take pictures, and then under the optical microscope. 


\subsection{Western blot analysis}

As previously described [24], the $\mathrm{L}_{4}-\mathrm{L}_{6}$ DRG neurons were lysed on ice in lysis buffer $(1 \mu$ PMSF in $100 \mu$ l RIPA buffer) supplemented with protease and phosphatase inhibitors. Protein concentration was determined using the BCA method. Samples were heated in boiling water for 5 minutes, separated using Tris-glycine denaturing gradient gel electrophoresis on $8 \%$ SDS-polyacrylamide gels, and transferred to polyvinylidene difluoride (PVDF) membranes (EMD Millipore, Billerica, MA, USA). The membranes were then blocked using $5 \%$ non-fat milk in TBS-Tween 20 (TBST) buffer $(\mathrm{pH} 8.0,10 \mathrm{mmol} / \mathrm{l}$ Tris- $\mathrm{HCl}, 150 \mathrm{mmol} / \mathrm{l} \mathrm{NaCl}$, and $0.2 \%$ Tween 20) for 2 hours at room temperature and probed using rabbit anti-Cav2.2 monoclonal antibody (1:5,00, 5\% non-fat milk) and rabbit anti-MT2 monoclonal antibody (1:1,000, $5 \%$ non-fat milk) overnight at $4{ }^{\circ} \mathrm{C}$. Then, the blots were washed 3 times with TBST for 5 minutes each and incubated with horseradish peroxidase-conjugated goat anti-mouse or goat anti-rabbit secondary antibodies $(1: 10,000)$ for 2 hours at room temperature. Enhanced chemiluminescence (Pierce) was used to detect the immune complexes. Protein levels were normalized to $\beta$-actin. The intensity of the bands was determined using Image $\mathrm{J}$ Launcher software (National Institutes of Health, USA).

1.8 Whole cell patch clamp recordings

Whole-cell patch-clamp recordings from DRG neurons were obtained using a MultiClamp 700B amplifier and Axon Digidata 1550A as previously described [25]. A cored borosilicate glass blank (Sutter Instruments) was selected and transformed into a microelectrode using a P-97 electrode drawing instrument. The microelectrode with a resistance value of 2-6 $\mathrm{M} \Omega$ was selected. The recorded signal was filtered at $2.5 \mathrm{kHz}$ and converted using a converter with a sampling frequency of $10-20 \mathrm{kHz}$.

For current-clamp recording [26], extracellular solution (140 $\mathrm{mM} \mathrm{NaCl}, 5 \mathrm{mM} \mathrm{KCl}, 2 \mathrm{mM} \mathrm{CaCl} 2,2 \mathrm{mM}$ $\mathrm{MgCl}_{2} \cdot \mathrm{H}_{2} \mathrm{O}, 10 \mathrm{mM}$ HEPES, $11 \mathrm{mM}$ glucose; $\mathrm{pH}$ adjusted to 7.4 using $\mathrm{NaOH}$ ) and pipette solution (135

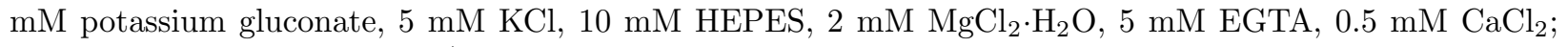
$\mathrm{pH}$ adjusted to 7.4 using $\mathrm{KOH}$ ) were used. The osmolality of all solutions was between 315 and $325 \mathrm{mOsm}$. In the current clamp mode, a step protocol from 0 to $500 \mathrm{pA}$ in $50 \mathrm{pA}$ increments was used to measure the current threshold (rheobase, the minimum current intensity required to excite the first action potential) with a pulse duration of $200 \mathrm{~ms}$. After that, another step protocol $2 \times$ rheobase (duration, $500 \mathrm{~ms}$; amplitude, double the strength of $1 \times$ rheobase) was performed to record the number of action potentials.

For voltage-clamp recording [27], external solution (150 mM TEA-Cl, $5 \mathrm{mM} \mathrm{CaCl} 2,0.8 \mathrm{mM} \mathrm{MgCl} 2 \cdot \mathrm{H}_{2} \mathrm{O}$, $10 \mathrm{mM}$ HEPES, $10 \mathrm{mM}$ D-glucose, $1 \mathrm{mM}$ 4-aminopyridine [to block potassium ion current]; $\mathrm{pH}$ adjusted to 7.35 using $\mathrm{CsOH})$ and internal solution $\left(135 \mathrm{mM} \mathrm{CsCl}, 1 \mathrm{mM} \mathrm{CaCl} 2,2 \mathrm{mM} \mathrm{MgCl} \mathrm{M}_{2} \cdot \mathrm{H}_{2} \mathrm{O}, 11 \mathrm{mM}\right.$ EGTA, $10 \mathrm{mM}$ HEPES, $10 \mu \mathrm{M}$ nimodipine [to block L-type $\mathrm{Ca}^{2+}$ channels; $\mathrm{pH}$ adjusted to 7.25 using $\mathrm{CsOH}$ and osmolality to $320 \mathrm{mOsm}$ using sucrose]. The recordings were performed at room temperature $\left(22-25{ }^{\circ} \mathrm{C}\right)$. In the voltage clamp mode for activation of N-type calcium channels, cells were held at $-60 \mathrm{mV}$ and voltage clamped at $-90 \mathrm{mV}$ for $100 \mathrm{~ms}$, and a step protocol (from -90 to $20 \mathrm{mV}$ in $10 \mathrm{mV}$ increments with a pulse duration of $500 \mathrm{~ms}$ ) was used. For the inactivation curve, currents were evoked by a test potential to 20 $\mathrm{mV}$ for $50 \mathrm{~ms}$ after a $500 \mathrm{~ms}$ pre-pulse at potentials ranging from -90 to $20 \mathrm{mV}$ with $10 \mathrm{mV}$ increments. The voltage dependencies of activation and steady-state inactivation were described using single Boltzmann distributions as per the following formulas:

Activation: $\mathrm{G}(\mathrm{V})=\mathrm{G}_{\max } /\left(1+\exp \left[-\left(\mathrm{V}-\mathrm{V}_{\mathbf{5 0}}\right) / \mathrm{k}\right]\right)$,

Inactivation: $\mathrm{I}(\mathrm{V})=\mathrm{I}_{\max } /\left(1+\exp \left[\left(\mathrm{V}-\mathrm{V}_{\mathbf{5 0}}\right) / \mathrm{k}\right]\right)$,

where, $\mathrm{G}_{\max }$ is the maximal conductance, $\mathrm{I}_{\max }$ is the maximal amplitude of current, $\mathrm{V}_{\mathbf{5 0}}$ is the voltage at which half the current is activated or inactivated, and $\mathrm{k}$ represents the voltage dependence (slope) of the distribution. The data were analyzed using Origin8 (Microcal Software, Northampton, MA)

1.9 Statistical analysis

SPSS Statistics 17.0 software was used for statistical analysis. In each experiment, data related to two DRG 
neurons were normalized according to the corresponding values from the left side of the Sham group. For the nociceptive behavior, data were analyzed using one-way repeated measures analysis of variance (ANOVA), and one-way ANOVA for different groups at the same time points were carried out. Data for patch clamp analysis, immunofluorescence experiments, and western blot analysis were analyzed using one-way ANOVA for multiple groups. All data are expressed as mean +- standard error of the mean. $\mathrm{P}$ value $<0.05$ was considered to be statistically significant.

\section{Results}

\subsection{Melatonin can suppress cold allodynia and reduce the expression of $N$-type calcium channel protein after SNI surgery}

Firstly, we used thermal stimulation (Hargreaves experiments) and acetone experiments to test pain related behavioral changes using the SNI model. We conducted the acetone experiments (shown in Fig. 1B). The results show that, compared with that in Sham group, the withdrawal duration in SNI + Vel group increased significantly $(\mathrm{F}=1438.042, \mathrm{P}<0.001, \mathrm{n}=9)$. But there were no significant differences between each group in terms of the TWL values $(\mathrm{F}=0.004, \mathrm{P}=0.955, \mathrm{n}=9$ ) (shown in Fig. 1A)

Then, rats were treated by i.p. injections of $50 \mathrm{mg} / \mathrm{kg}$ melatonin for 21 days to investigate the changes in nociceptive behavior after SNI surgery; in the SNI + Vel group, we injected the same volume of the vehicle. Subsequently, immunofluorescence and western blot experiments were conducted. Melatonin can significantly suppress cold allodynia (SNI + Vel group vs. SNI + Mel group, $\mathrm{F}=37.117, \mathrm{P}<0.005)$. However, the effect of melatonin can be inhibited significantly by the MT2 receptor blocker 4-P-PDOT (SNI + Mel + $4 \mathrm{PP}$ group vs. $\mathrm{SNI}+\mathrm{Mel}$ group, $\mathrm{F}=15.515, \mathrm{P}<0.05$ ) (shown in Fig. $1 \mathrm{~A}$ and $\mathrm{B}$ ).

\subsection{MT2 receptor and Cav2.2 exhibit the same expression patterns in rat DRG neurons}

As shown in Fig. 2, immunofluorescence was carried out to observe the expression of Cav2.2 and MT2 in the same DRG neurons. Furthermore, in order to clearly indicate the type of DRG neurons, we used calcitonin gene-related peptide (CGRP), isolectin B4 (IB4), and neurofilament-200 (NF200) to mark the neurons. Fig. 3A and Fig. 3B show the co-expression of Cav2.2 and MT2 with NF-200, CGRP, and IB4 in $\mathrm{L}_{4}-\mathrm{L}_{6}$ DRG neurons; Fig. 3C shows histograms representing cell diameter measurements in high Cav2.2expressing neurons, demonstrating that $65.86+-2.34 \%$ cells had a diameter of $10-20 \mu \mathrm{m}, 23.14 \pm 1.94 \%$ had a diameter of $20-40 \mu \mathrm{m}$, and $11.00 \pm 2.31 \%$ had a diameter greater than $40 \mu \mathrm{m}$. Fig. 3D shows the histograms representing cell diameter measurements in MT2-expressing neurons, demonstrating that 61.00 $\pm 2.21 \%$ cells had a diameter of $10-20 \mu \mathrm{m}, 28.01 \pm 1.97 \%$ had a diameter of $20-40 \mu \mathrm{m}$, and $12.33 \pm 1.45 \%$ had a diameter greater than $40 \mu \mathrm{m}$. Therefore, immunofluorescence staining verified that Cav2.2 and MT2 were mainly expressed in small and medium-sized DRG neurons; this led us to decide that these were the cells that we needed to study next.

\subsection{After SNI surgery, the expression of Cav2.2 increased in $\mathrm{L}_{4}-\mathrm{L}_{6}$ DRG neurons}

To observe the changes in the levels of the Cav2.2 protein in DRG neurons of rats after SNI surgery, next, we conducted the immunofluorescence and western blot experiments.

As shown in Fig. 4A, Cav2.2 were expressed in $\mathrm{L}_{4}$ - $\mathrm{L}_{6}$ DRG neurons (Immunofluorescence experiment). Compared with that in the Sham group $(1.02 \pm 0.06)$, the fluorescence intensity ratio of Cav2.2 was significantly increased at days $7(1.26 \pm 0.01, \mathrm{P}<0.05), 14(2.13 \pm 0.07, \mathrm{P}<0.001)$, and $21(2.20 \pm 0.06, \mathrm{P}<0.001)$ after SNI surgery (shown in Fig. 4 C).

As shown in Fig. $4 \mathrm{~B}$, the western-blot experiment also verified the protein expression patterns in $\mathrm{L}_{4}-\mathrm{L}_{6}$ DRG neurons. Compared with that in the Sham group $(1.02 \pm 0.02)$, the relative density of Cav2.2 was significantly increased at days $7(1.91 \pm 0.02, \mathrm{P}<0.05), 14(2.88 \pm 0.10, \mathrm{P}<0.001)$, and $21(2.91 \pm 0.13$, $\mathrm{P}<0.001$ ) after SNI surgery (shown in Fig. $4 \mathrm{D}$ ). As the 21-day changes were the most significant, we selected 21-day rats as the study subjects for the subsequent experiments.

2.4 Melatonin inhibits the increase in $\mathrm{L}_{4}-\mathrm{L}_{6}$ DRG neuron frequency of action potentials after SNI surgery 
Furthermore, in order to clarify the changes in the excitability of DRG neurons after SNI surgery, we used the whole-cell patch clamp method to estimate the excitability of $\mathrm{L}_{4}-\mathrm{L}_{6}$ DRG neurons. In current clamp mode, we used the rheobase (the minimum current intensity required to excite the first action potential) and the number of action potentials as indicators of the excitability of DRG neurons.

After the SNI surgery, compared with that in the sham group $(366.67 \pm 10.54 \mathrm{pA})$, the $1 \times$ rheobase action potentials were significantly decreased in the SNI + Vehicle group $(100 \pm 12.91 \mathrm{pA}, \mathrm{P}<0.001)$ (shown in Fig. $5 \mathrm{C})$. Furthermore, the number of action potentials increased significantly in $2 \times$ rheobase group (18.83 \pm 0.60 , $\mathrm{P}<0.001)$ compared with that in Sham group $(2.83 \pm 0.31)$ (shown in Fig. 5D). Compared with the SNI + Vehicle group, the result show that different concentrations of melatonin have different effects on DRG neurons by increasing the $1 \times$ rheobase of action potentials $(0.1 \mu \mathrm{M}, 166.67 \pm 10.54 \mathrm{pA}, \mathrm{P}<0.01 ; 1 \mu \mathrm{M}, 250.00$ $\pm 12.91 \mathrm{pA}, \mathrm{P}<0.001 ; 10 \mu \mathrm{M}, 258.33 \pm 15.37 \mathrm{pA}, \mathrm{P}<0.001)$. Moreover, the number of action potentials reduced significantly $(0.1 \mu \mathrm{M}, 12 \pm 0.63, \mathrm{P}<0.05 ; 1 \mu \mathrm{M}, 7.17 \pm 0.40, \mathrm{P}<0.001 ; 10 \mu \mathrm{M}, 5.00 \pm 0.37, \mathrm{P}<0.001)$ in $2 \times$ rheobase (shown in Fig. $5 \mathrm{C}$ and $\mathrm{D}$ ).

In addition, administration of NP118809 (N-type calcium channel blocker) also increased the $1 \times$ rheobase of action potentials $(333.33 \pm 25.82 \mathrm{pA}, \mathrm{P}<0.001)$ and decreased the number of the action potentials $(2 \times$ rheobase $)$ significantly $(4.33 \pm 0.82, \mathrm{P}<0.001)$ compared with those in $\mathrm{SNI}+$ Vehicle group. Furthermore, in order to demonstrate the role of the MT2 receptor, we used MT2 receptor antagonist 4-P-PDOT $(0.1 \mu \mathrm{M})$ co-incubation with DRG neurons for 30 minute, irrigated the cells using extracellular fluid containing $10 \mu \mathrm{M}$ melatonin for 1 minute, and then recorded the action potentials and the number of the action potentials. The results showed that, compared with SNI + Vehicle group, 4-P-PDOT group had reduced effects of melatonin on DRG neurons in terms of the $1 \times$ rheobase $(133.75 \pm 40.82 \mathrm{pA}, \mathrm{P}=0.1449)$, and the $2 \times$ rheobase $(11.83 \pm$ $1.47, \mathrm{P}<0.001)$ of action potentials. Fig. $5 \mathrm{E}$ shows that no change was detected in the resting potentials in each group. $10 \mu \mathrm{M}$ melatonin had the biggest effect on DRG neurons in our study, and 4-P-PDOT could not block thenegativeeffect of melatonin completely ( $\mathrm{n}=6$ neurons in every group).

2.5 A left shift was observed in the N-type calcium channel current activation curve in $\mathrm{L}_{4}$ - $\mathrm{L}_{6} \mathrm{DRG}$ neurons after SNI surgery

Next, we investigated the $\mathrm{L}_{4}-\mathrm{L}_{6}$ DRG neuron N-type calcium channels after SNI surgery in the voltage clamp mode. Furthermore, the activation curve was hyperpolarized with the $\mathrm{V}_{\mathbf{5 0}}$ left-shifted from $-10.23 \pm 3.28$ $\mathrm{mV}(\mathrm{k}=27.18 \pm 6.26)$ in the Sham group to $-21.19 \pm 4.67 \mathrm{mV}(\mathrm{k}=18.51 \pm 4.61)$ in the SNI group (shown in Fig. 6C); the inactivation curve was not significantly shifted in SNI group vs. Sham group $(\mathrm{P}=0.37$ ) (shown in Fig. 6D). The current density of peak Cav2.2 current was increased in SNI group $(-90.42 \pm 8.49 \mathrm{mV})$ at $-10 \mathrm{mV}$ compared with that in Sham group $(-45.68 \pm 8.34 \mathrm{mV}$ ) at $0 \mathrm{mV}$ (shown in Fig. 6E). Particularly, $0.1 \mu \mathrm{M}$ NP118809 was observed to block Cav2.2 current specifically, and Cav2.2 current recovered after extracellular fluid was used to washout DRG cells for $30 \mathrm{sec}$ (shown in Fig. 6A and B). This means that the use of our stimulation of step protocol can enable the recording of relatively pure Cav2.2 calcium currents. At the same time, we used $10 \mu \mathrm{M}$ nimodipine in internal solution and $1 \mathrm{mM} 4$-aminopyridine in external solution to block L-type $\mathrm{Ca}^{2+}$ and potassium ion currents, respectively.

2.6 Melatonin reduce the expression of N-type calcium channel protein after SNI surgery by MT2 receptor

To further clarify the possible role of the MT2 receptor, next, we performed W-B and immunofluorescence experiments, as shown in Fig. 7A immunofluorescence experiment were conducted, and Fig. 7C shown the fluorescence intensity ratios of Cav2.2 and the corresponding days for Sham group $(1.00 \pm 0.02)$, SNI + Vel group (1.59 $\pm 0.09, \mathrm{P}<0.05$ compared with Sham group), and SNI + Mel group $(1.13 \pm 0.04, \mathrm{P}<0.05$ compared with SNI + Vel group). The expression levels (shown in Fig. 7B) and relative density of Cav2.2 ( shown in Fig. 7D) in each group are also shown for Sham group (1.02 \pm 0.06$)$, SNI + Vel group $(2.75 \pm$ 0.09 , compared with SNI group $\mathrm{P}=0.7585)$, and $\mathrm{SNI}+$ Mel group $(1.15 \pm 0.07, \mathrm{P}<0.05$ compared with SNI + Vel group). This indicates that melatonin can reduce the expression of the N-type calcium channel protein after SNI surgery. However, the inhibitory effect of melatonin was weakened significantly after 4P-PDOT administration, suggesting that melatonin can inhibit the increase of Cav2.2 protein expression after SNI 
through the MT2 receptor.

2.7 Melatonin $(10 \mu \mathrm{M})$ induced a significant left shift in the N-type calcium channel inactivation curve of DRG neurons

Next, we investigated the effect of melatonin on the voltage-dependence of activation and inactivation of $\mathrm{N}$-type calcium channel potential duration in DRG neurons. Fig. 8A shows the representative current of N-type calcium channels in $\mathrm{L}_{4}-\mathrm{L}_{6}$ DRG neurons after SNI obtained using depolarizing step pulse from -90 $\mathrm{mV}$ to $20 \mathrm{mV}$ for $500 \mathrm{~ms}$ (up) and a test potential of $20 \mathrm{mV}$ for $50 \mathrm{~ms}$ after a $500 \mathrm{~ms}$ pre-pulse at potentials ranging from -90 to $0 \mathrm{mV}$ with $10 \mathrm{mV}$ increments (down). Extracellular fluid containing $10 \mu \mathrm{M}$ melatonin was used to irrigate DRG neurons for $15 \mathrm{sec}$. Net current represents the traces obtained by subtracting the $10 \mu \mathrm{M}$ melatonin traces from the Before traces. Washout represents the use of extracellular fluid to wash DRG neurons for 1 minute.

Fig. 8B, C, and D show the effects of melatonin on calcium currents. In Fig. 8B, the activation curves are unchanged between Sham group (black trace; $\mathrm{V}_{\mathbf{5 0}}=-10.72 \pm 4.52 \mathrm{mV}, \mathrm{k}=23.01 \pm 3.39$ ), Sham $+10 \mu \mathrm{M}$ Mel group (red trace; $\mathrm{V}_{\mathbf{5 0}}=-10.59 \pm 10.67 \mathrm{mV}, \mathrm{k}=27.38 \pm 8.30$ ), SNI group (blue trace; $\mathrm{V}_{\mathbf{5 0}}=-20.96 \pm$ $4.57 \mathrm{mV}, \mathrm{k}=26.13 \pm 5.02$ ), and $\mathrm{SNI}+10 \mu \mathrm{M}$ Mel group (green trace; $\mathrm{V}_{\mathbf{5 0}}=-22.32 \pm 3.8 \mathrm{mV}, \mathrm{k}=25.80 \pm$ 4.34). The inactivation curve in Fig. 8C was hyperpolarized, with the $\mathrm{V}_{\mathbf{5 0}}$ left-shifted from $12.65 \pm 3.32 \mathrm{mV}$ $(\mathrm{k}=26.85 \pm 8.52)$ in Sham group (black trace) to $-41.31 \pm 2.41 \mathrm{mV}(\mathrm{k}=21.90 \pm 3.51)$ in Sham $+10 \mu \mathrm{M}$ Mel group (red trace, $\mathrm{P}<0.001$ vs. Sham group) and the $\mathrm{V}_{\mathbf{5 0}}$ left-shifted from $11.51 \pm 0.48 \mathrm{mV}(\mathrm{k}=24.07 \pm$ $3.78)$ in the SNI group (blue trace) to $-37.55 \pm 3.16 \mathrm{mV}(\mathrm{k}=23.35 \pm 4.28)$ in $\mathrm{SNI}+10 \mu \mathrm{M}$ Mel group (green trace, $\mathrm{P}<0.001$ vs. SNI group). Fig. $8 \mathrm{D}$ shows the current density $(\mathrm{pA} / \mathrm{pF})$ of Cav2.2 current in each group: Sham group $(-45.74 \pm 6.78$, black trace), Sham $+10 \mu \mathrm{M}$ Mel group $(-20.48 \pm 6.89$, red trace, $\mathrm{P}<0.001$ vs. Sham group), SNI group (-90.42 \pm 8.49 , blue trace), and SNI $+10 \mu \mathrm{M}$ Mel group (-31.25 \pm 0.10 , green trace, $\mathrm{P}<0.001$ vs. SNI group). Therefore, we conclude that $10 \mu \mathrm{M}$ melatonin can inhibit the Cav2.2 current and promote the inactivation of Cav2.2 channels.

\section{Discussion}

Our main findings are as follows: 1) Cav2.2 and MT2 are co-expressed in small and medium-sized DRG neurons in rats; 2) After SNI surgery, the withdrawal duration of cold allodynia increased, and this can be inhibited by melatonin; 3) The expression of Cav2.2 increased in DRG neurons, and melatonin inhibited the expression of Cav2.2 after SNI surgery; 4) Melatonin can inhibit the increase in $\mathrm{L}_{4}-\mathrm{L}_{6}$ DRG neuron frequency of action potentials after SNI surgery; 5) The N-type calcium channel current activation curve shifts left in $\mathrm{L}_{4^{-}}$ $\mathrm{L}_{6}$ DRG neurons after SNI surgery; 6) Melatonin significantly shifts the N-type calcium channel inactivation curve of DRG neurons to left. These results revealed that melatonin inhibits neuropathic pain via the MT2 receptor by reducing the excitability of neurons and accelerating the inactivation of N-type calcium channels.

Neuropathic pain usually manifests in a variety of clinical features, including the formation of zones of local or complete sensory loss, different types of induced pain, burning pain, pain aggravation after repeated stimulation, and persistent pain after stimulation $[1,28]$. Abnormal pain (pain caused by stimuli that normally do not cause pain) and hyperalgesia (increased pain response caused by stimuli that normally cause pain) are two other prominent symptoms of neuropathic pain [29, 30]. Abnormal pain and hyperalgesia are classified as mechanical (dynamic, dotted, and static) or thermal (cold and hot) stimuli that cause pain and have independent mechanisms. The molecular mechanisms of mechanical allodynia and thermal hyperalgesia are also different. In our study, we first built the SNI model and tested the latency of heat allodynia and the withdrawal duration of cold allodynia using acetone; the results showed that the withdrawal duration of cold allodynia increased clearly 3 days post-surgery, but there was no change in heat allodynia between SNI group and Sham group. The reason may be that the SNI model damages nerve fibers differently - thermal stimulation is mediated by $\mathrm{C}$ fibers and A $\delta$ fibers, while mechanical aberrant pain is thought to be mediated by low threshold $\mathrm{A} \beta$ fibers $[29,30]$. However, thermal threshold is not typical of most neuropathic pain, and 
it is usually considered to refer to changes in the sensitivity of the peripheral pain receptors rather than to changes in the overall excitability of the somatosensory system [31].

Many ion channels facilitate the detection and processing of pain signals. Some of these are permeable for calcium ions [32], which in turn mediate a range of cellular signaling functions, such as neurotransmitter release [33], calcium-dependent enzyme activation [34], and calcium-dependent changes in gene expression [35]. Thus, abnormal calcium signaling is a critical step in altering neural network activity involved in pain regulation, and these changes form the cellular basis for chronic pain. As we all know, voltage-gated calcium channels are the main channels for depolarization-mediated calcium entry into neurons. N-type calcium channels are expressed almost exclusively in neuronal tissue and are enriched at presynaptic nerve endings, where they trigger the release of neurotransmitters through physical involvement in synaptic release mechanisms $[16,36,37]$. Calcium entry into the synaptic nerve terminals releases neurotransmitters such as glutamate, Calcitonin Gene-Related Peptide (CGRP), and P substance (SP) [38-40]. Therefore, inhibition of $\mathrm{N}$-type channel activity leads to reduced neurotransmission, resulting in analgesia. However, the expression and function of Cav2.2 in DRG neurons has not been extensively studied,particularly, with regard to the characteristics of electrophysiological Cav2.2 currents.

In our study, in order to prove the relationship between MT2 receptor and Cav2.2, we first proved the coexpression of the MT2 receptor and Cav2.2 in DRG neurons (shown in Fig. 2). Both Cav2.2 (shown in Fig. 3A) and MT2 are mainly expressed in the small and medium neurons (shown in Fig. 3B), which agrees with the results of the study by Lin et al. [41]. After SNI surgery, we tested the latency of heat allodynia and the withdrawal duration of cold allodynia; compared with those in Decosterd's study [17], the behavioral tests we used are relatively unitary, but the results were the same as theirs experimental results (shown in Fig. 1), with increased expression of Cav2.2 in DRG neurons (shown in Fig. 4) and increased Cav2.2 currents (shown in Fig. 6). Administration of melatonin can inhibit the duration of cold allodynia in rats after SNI surgery (shown in Fig. 1), and at the same time melatonin can reduce the up-regulated expression of Cav2.2 (shown in Fig. 7). Furthermore, administration of melatonin can inhibit the increased excitability (shown in Fig. 5) and Cav2.2 current (shown in Fig. 8) of DRG neurons in rats after SNI surgery. This is consistent with the results of a study by Huang et al., in which melatonin was found to have an inhibitory effect on the neuronal excitability of TG neurons in rats [42]. Suppressing neuronal excitability may be one of the properties of melatonin; the MT2 receptor blocker 4-P-PDOT can reduce the negative effects of melatonin on DRG neurons significantly (shown in Fig. 5 and Fig. 1). All the results suggested that melatonin can accelerate the inactivation of Cav2.2 to inhibit calcium currents via the MT2 receptor pathway. Fig. 9 shows the schematic diagram of the effect of melatonin on Cav2.2 channels in DRG neurons of rats. MT2 receptor and Cav2.2 are expressed on the same neurons, and melatonin activates the MT2 receptor to reduce the Cav2.2 current by accelerating Cav2.2 inactivation (shown in Fig. 9A). After SNI surgery, the Cav2.2 expression level and current and the excitability of DRG neurons increased, and the left shift of the Cav2.2 channel activation curve represents that it became easier to open (shown in Fig. 9B). Melatonin reduced the expression and the current of Cav2.2 and decreased the excitability of DRG neurons. At the same time, the left shift of the inactivation curve of Cav2.2 channelprove that it became easier to close (shown in Fig. 9C). Studies have shown that four mechanisms underlie the effects of melatonin: binding to melatonin receptors on the plasma membrane, binding to intracellular proteins such as calmodulin, binding to orphan nuclear receptors, and the antioxidant effect [11]. One of these mechanisms might be responsible for melatonin inhibiting the Cav2.2 current and excitability of DRG neurons, as melatonin has multiple receptors and different effects. Previous research has shown there are three main types of melatonin receptors: Melatonin receptor type 1a: MT1 (on the cell membrane), Melatonin receptor type 1b: MT2 (on the cell membrane), and retinoid-related orphan nuclear hormone receptor: RZR/ROR $\alpha$. These melatonin receptors are found in the brain, retina, kidney, cells of the immune system, epithelial prostate cancer and breast cancer cells, and so on $[43,44]$. Differences in the presence of the receptor result in different effects of the receptor. In recent years, more and more studies have shown that melatonin can inhibit pain in different ways [12]. Zhang et al. provide direct evidence that melatonin attenuates Cav3.2 T-type currents through stimulation of the MT2 receptor and via the G $\beta \gamma$-mediated activation of $\mathrm{PKC} \eta$ in small diameter TG neurons [45]. 
However, in our study, we preliminarily demonstrated that melatonin inhibits Cav2.2 current through MT2 receptors; the changes in downstream factors need to be further verified. However, melatonin also combines with intracellular proteins such as calmodulin and binds to orphan nuclear receptors. Lin et al. suggest that melatonin could suppress neuropathic pain via MT2-independent pathways in DRG neurons after cuff surgery, but ROR $\alpha$ activation by high concentrations of melatonin inhibited the down-regulation of MAPK1 and calcium channels via MT2 [41]. Similarly, in our study, we confirmed that MT2 receptors are mainly expressed in rat DRG neurons, but not MT1 receptor (Supplement Figure). Abla Benleulmi-Chaachoua and his team show that MT1 is part of the presynaptic protein network and negatively regulates Cav2.2 activity in hippocampi of rat embryos, providing a first hint for potential synaptic functions of MT1 [46]. However, Luca Posa's results show that the genetic inactivation of MT2, but not MT1 receptors, produces a distinct effect on nociceptive threshold in mouse, suggesting that the MT2 melatonin receptor subtype is selectively involved in the regulation of pain responses [47]. The reason for this is probably due to the inconsistent distribution and function of MT receptors in peripheral neurons and central neurons. What's more, this may be because different concentrations of melatonin have different effects and mechanisms of action; this aspect is also what we need to study next. And a potential mechanism which deserves special mention is one involving the collapsin response mediator protein (CRMP2), which becomes the central node in the assembly of several noxious signal complexes, including Cav2.2 and Nav1.7. For voltage-dependent ion channels, the expression level of CRMP2 and phosphorylation level of Cdk5 alters calcium influx and the depolarization-induced calcium current in cortical neurons [48, 49]. Moreover, the expression of CRMP2 is altered in neurodegenerative diseases, and these proteins may be important in the physiological pathology of the adult nervous system [50]. Therefore, the relationship between melatonin and CRMP2 needs to be further determined.

In summary, ononehand our study demonstrated that melatonin inhibits neuropathic pain via the MT2 receptor by reducing Cav2.2 expression and excitability in DRG neurons. $O$ ntheotherhand, melatonin inhibits neuropathic pain by accelerating the inactivation and current of N-type calcium channels. This finding is expected to provide a new target for treatment therapies for neuropathic pain using melatonin. However, the shortcoming of this study is that the mechanism which leads to increased expression of Cav2.2 remains unknown. Furthermore, it remains to be further studied whether melatonin treatment can inhibit neuropathic pain by reducing neurotransmitter release and excitability of primary sensory neurons to reduce the sensitization of the central nervous system.

\section{Acknowledgment}

This work was supported by the National Natural Science Foundation of China grant No. 81560081 (to JQS). The authors would like to express their thanks to all those who helped in writing this paper. The funding sources had no role in study design, conception, analysis or interpretation of data, or writing and deciding to submit this paper for publication.

\section{Ethics Statement}

Animal experiments were conducted with approval of the Institutional Ethics Review Board at the First Affiliated Hospital of the Shihezi University School of Medicine and were carried out according to the Ethical Guidelines for Investigations of Experimental Pain in Conscious Animals of the International Association for the Study of Pain.

\section{Conflict of Interest}

The authors declare that the research was conducted in the absence of any commercial or financial relationships that could be construed as a potential conflict of interest.

\section{Author Contributions}


JUN-JIE TIAN and CHAO-YANG TAN and YING-YING ZHANG are contributed equally to the conception or design of the work; or the acquisition, analysis or interpretation of data for the work;

YING ZHOU, NAN CAO, ZU-WEI QU, XUE-ER YANG, drafting the work or revising it critically for important intellectual content;

LI-CANG ZHU and LI LI and KE-TAO MA provide approval for publication of the content;

JUN-QIANG SI agree to be accountable for all aspects of the work in ensuring that questions related to the accuracy or integrity of any part of the work are appropriately investigated and resolved.

\section{References}

1 TS Jensen, R Baron, M Haanpää, E Kalso, JD Loeser, AS Rice, et al. A new definition of neuropathic pain. Pain. 2011;152(10):2204-5.

2 N Torrance, BH Smith, MI Bennett, AJ Lee. The epidemiology of chronic pain of predominantly neuropathic origin. Results from a general population survey. The journal of pain : official journal of the American Pain Society. 2006;7(4):281-9.

3 D Bouhassira, M Lantéri-Minet, N Attal, B Laurent, C Touboul. Prevalence of chronic pain with neuropathic characteristics in the general population. Pain. 2008;136(3):380-7.

4 D Bouhassira. Neuropathic pain: Definition, assessment and epidemiology. Revue neurologique. 2019;175(null):16-25.

5 BP Bean. Pharmacology of calcium channels in cardiac muscle, vascular muscle, and neurons. American journal of hypertension. 1991;4(null):406S-11S.

6 WA Catterall, E Perez-Reyes, TP Snutch, J Striessnig. International Union of Pharmacology. XLVIII. Nomenclature and structure-function relationships of voltage-gated calcium channels. Pharmacological reviews. 2005;57(4):411-25.

7 TJ Bell, C Thaler, AJ Castiglioni, TD Helton, D Lipscombe. Cell-specific alternative splicing increases calcium channel current density in the pain pathway. Neuron. 2004;41(1):127-38.

8 S Lee. Pharmacological Inhibition of Voltage-gated $\mathrm{Ca}(2+)$ Channels for Chronic Pain Relief. Current neuropharmacology. 2013;11(6):606-20.

9 R Vickers-Smith, J Sun, RJ Charnigo, MR Lofwall, SL Walsh, JR Havens. Gabapentin drug misuse signals: A pharmacovigilance assessment using the FDA adverse event reporting system. Drug and alcohol dependence. 2019; undefined(undefined):107709.

10 B Guardiola-Lemaitre. Toxicology of melatonin. Journal of biological rhythms. 1997;12(6):697-706.

11 M Emet, H Ozcan, L Ozel, M Yayla, Z Halici, A Hacimuftuoglu. A Review of Melatonin, Its Receptors and Drugs. The Eurasian journal of medicine. 2016;48(2):135-41.

12 S Comai, M Lopez-Canul, D De Gregorio, A Posner, M Ettaoussi, FC Guarnieri, et al. Melatonin MT receptor as a novel target in neuropsychopharmacology: MT ligands, pathophysiological and therapeutic implications, and perspectives. Pharmacological research. 2019;144(undefined):343-56.

13 B Altiparmak, H Cil, N Celebi. [Effect of melatonin on the daytime sleepiness side-effect of gabapentin in adults patients with neuropathic pain]. Revista brasileira de anestesiologia. 2019;69(2):137-43.

14 B Chovancova, S Hudecova, L Lencesova, P Babula, I Rezuchova, A Penesova, et al. Melatonin-Induced Changes in Cytosolic Calcium Might be Responsible for Apoptosis Induction in Tumour Cells. Cellular physiology and biochemistry : international journal of experimental cellular physiology, biochemistry, and pharmacology. 2017;44(2):763-77. 
15 H Zhu, Q Jin, Y Li, Q Ma, J Wang, D Li, et al. Melatonin protected cardiac microvascular endothelial cells against oxidative stress injury via suppression of IP3R-[Ca]c/VDAC-[Ca]m axis by activation of MAPK/ERK signaling pathway. Cell stress \& chaperones. 2018;23(1):101-13.

16 RE Westenbroek, JW Hell, C Warner, SJ Dubel, TP Snutch, WA Catterall. Biochemical properties and subcellular distribution of an N-type calcium channel alpha 1 subunit. Neuron. 1992;9(6):1099-115.

17 I Decosterd, CJ Woolf. Spared nerve injury: an animal model of persistent peripheral neuropathic pain. Pain. 2000;87(2):149-58.

18 SH Kim, JM Chung. An experimental model for peripheral neuropathy produced by segmental spinal nerve ligation in the rat. Pain. 1992;50(3):355-63.

19 Y Shir, Z Seltzer. Effects of sympathectomy in a model of causalgiform pain produced by partial sciatic nerve injury in rats. Pain. 1991;45(3):309-20.

20 ME Onger, S Kaplan, ÖG Deniz, G Altun, BZ Altunkaynak, K Balcı, et al. Possible promoting effects of melatonin, leptin and alcar on regeneration of the sciatic nerve. Journal of chemical neuroanatomy. 2017;81(undefined):34-41.

21 M Zhang, CX Gao, YP Wang, KT Ma, L Li, JW Yin, et al. The association between the expression of PAR2 and TMEM16A and neuropathic pain. Molecular medicine reports. 2018;17(3):3744-50.

22 M Norcini, A Sideris, LA Martin Hernandez, J Zhang, TJ Blanck, E Recio-Pinto. An approach to identify microRNAs involved in neuropathic pain following a peripheral nerve injury. Frontiers in neuroscience. 2014;8(undefined):266.

$23 \mathrm{Y}$ Wang, H Zhu, K Ma, J Si, L Li. [Effects of acute hypoxia on potassium channels in spiral ganglion cells of SD rats]. Zhonghua er bi yan hou tou jing wai ke za zhi $=$ Chinese journal of otorhinolaryngology head and neck surgery. 2015;50(10):823-8.

24 QY Chen, CY Tan, Y Wang, KT Ma, L Li, JQ Si. Mechanism of persistent hyperalgesia in neuropathic pain caused by chronic constriction injury. Neural regeneration research. 2019;14(6):1091-8.

25 G Berecki, L Motin, DJ Adams. Mechanism of direct Cav2.2 channel block by the $x$-opioid receptor agonist U50488H. Neuropharmacology. 2016;109(undefined):49-58.

26 J Yang, MX Xie, L Hu, XF Wang, JZ Mai, YY Li, et al. Upregulation of N-type calcium channels in the soma of uninjured dorsal root ganglion neurons contributes to neuropathic pain by increasing neuronal excitability following peripheral nerve injury. Brain, behavior, and immunity. 2018;71(undefined):52-65.

27 S Zhang, L Yang, K Zhang, X Liu, W Dai, C Zhang, et al. ZC88, a novel N-type calcium channel blocker from 4-amino-piperidine derivatives state-dependent inhibits Cav2.2 calcium channels. Brain research. 2015;1605(undefined):12-21.

28 TS Jensen, R Baron. Translation of symptoms and signs into mechanisms in neuropathic pain. Pain. 2003;102(null):1-8.

29 TS Jensen, NB Finnerup. Allodynia and hyperalgesia in neuropathic pain: clinical manifestations and mechanisms. The Lancet Neurology. 2014;13(9):924-35.

30 A Truini, L Garcia-Larrea, G Cruccu. Reappraising neuropathic pain in humans-how symptoms help disclose mechanisms. Nature reviews Neurology. 2013;9(10):572-82.

31 AF Bourquin, M Süveges, M Pertin, N Gilliard, S Sardy, AC Davison, DR Spahn, I Decosterd. Assessment and analysis of mechanical allodynia-like behavior induced by spared nerve injury (SNI) in the mouse. Pain. 2006; 122:14. e1.

32 RM Eglen, JC Hunter, A Dray. Ions in the fire: recent ion-channel research and approaches to pain therapy. Trends in pharmacological sciences. 1999;20(8):337-42. 
33 E Neher, T Sakaba. Multiple roles of calcium ions in the regulation of neurotransmitter release. Neuron. 2008;59(6):861-72.

34 A Ghosh, ME Greenberg. Calcium signaling in neurons: molecular mechanisms and cellular consequences. Science (New York, NY). 1995;268(5208):239-47.

35 DG Wheeler, RD Groth, H Ma, CF Barrett, SF Owen, P Safa, et al. Ca(V)1 and $\mathrm{Ca}(\mathrm{V}) 2$ channels engage distinct modes of $\mathrm{Ca}(2+)$ signaling to control CREB-dependent gene expression. Cell. 2012;149(5):1112-24.

36 MC Nowycky, AP Fox, RW Tsien. Three types of neuronal calcium channel with different calcium agonist sensitivity. Nature. 1985;316(6027):440-3.

37 DB Wheeler, A Randall, RW Tsien. Roles of N-type and Q-type Ca2+ channels in supporting hippocampal synaptic transmission. Science (New York, NY). 1994;264(5155):107-11.

38 AR Evans, GD Nicol, MR Vasko. Differential regulation of evoked peptide release by voltage-sensitive calcium channels in rat sensory neurons. Brain research. 1996;712(2):265-73.

39 CA Maggi, M Tramontana, R Cecconi, P Santicioli. Neurochemical evidence for the involvement of Ntype calcium channels in transmitter secretion from peripheral endings of sensory nerves in guinea pigs. Neuroscience letters. 1990;114(2):203-6.

40 MT Smith, PJ Cabot, FB Ross, AD Robertson, RJ Lewis. The novel N-type calcium channel blocker, AM336, produces potent dose-dependent antinociception after intrathecal dosing in rats and inhibits substance P release in rat spinal cord slices. Pain. 2002;96:119-27.

41 JJ Lin, Y Lin, TZ Zhao, CK Zhang, T Zhang, XL Chen, et al. Melatonin Suppresses Neuropathic Pain via MT2-Dependent and -Independent Pathways in Dorsal Root Ganglia Neurons of Mice. Theranostics. 2017;7(7):2015-32.

42 F Huang, XY Guan, Y Yan, WG Fan, YY You, HW He, et al. Electrophysiological effects of melatonin on rat trigeminal ganglion neurons that participate in nociception in vitro. European review for medical and pharmacological sciences. 2018;22(10):3234-9.

43 T Uz, AD Arslan, M Kurtuncu, M Imbesi, M Akhisaroglu, Y Dwivedi, et al. The regional and cellular expression profile of the melatonin receptor MT1 in the central dopaminergic system. Brain research Molecular brain research. 2005;136(null):45-53.

$44 \mathrm{R}$ Hardeland. Melatonin in aging and disease -multiple consequences of reduced secretion, options and limits of treatment. Aging and disease. 2012;3(2):194-225.

45 Y Zhang, H Ji, J Wang, Y Sun, Z Qian, X Jiang, et al. Melatonin-mediated inhibition of Cav3.2 T-type Ca channels induces sensory neuronal hypoexcitability through the novel protein kinase C-eta isoform. Journal of pineal research. 2018;64(4): e12476.

46 A Benleulmi-Chaachoua, L Chen, K Sokolina, K Wong, I Jurisica, MB Emerit, M Darmon, A Espin, I Stagljar, P Tafelmeyer, et al. Protein interactome mining defines melatonin MT1 receptors as integral component of presynaptic protein complexes of neurons. Journal of pineal research. 2016;60(1):95-108.

47 L Posa, M Lopez-Canul, L Rullo, D De Gregorio, S Dominguez-Lopez, M Kaba Aboud, FF Caputi, S Candeletti, P Romualdi, G Gobbi. Nociceptive responses in melatonin MT receptor knockout mice compared to MT and double MT /MT receptor knockout mice. Journal of pineal research. 2020;69(3): e12671.

48 P Feldman, R Khanna. Challenging the catechism of therapeutics for chronic neuropathic pain: Targeting CaV2.2 interactions with CRMP2 peptides. Neuroscience letters. 2013;null(undefined):27-36.

$49 \mathrm{~J} \mathrm{Yu}$, A Moutal, A Dorame, SS Bellampalli, A Chefdeville, I Kanazawa, et al. Phosphorylated CRMP2 Regulates Spinal Nociceptive Neurotransmission. Molecular neurobiology. 2019;56(7):5241-55. 
50 JP Ip, AK Fu, NY Ip. CRMP2: functional roles in neural development and therapeutic potential in neurological diseases. The Neuroscientist : a review journal bringing neurobiology, neurology and psychiatry. 2014;20(6):589-98.

Figure Legends

Figure 1.
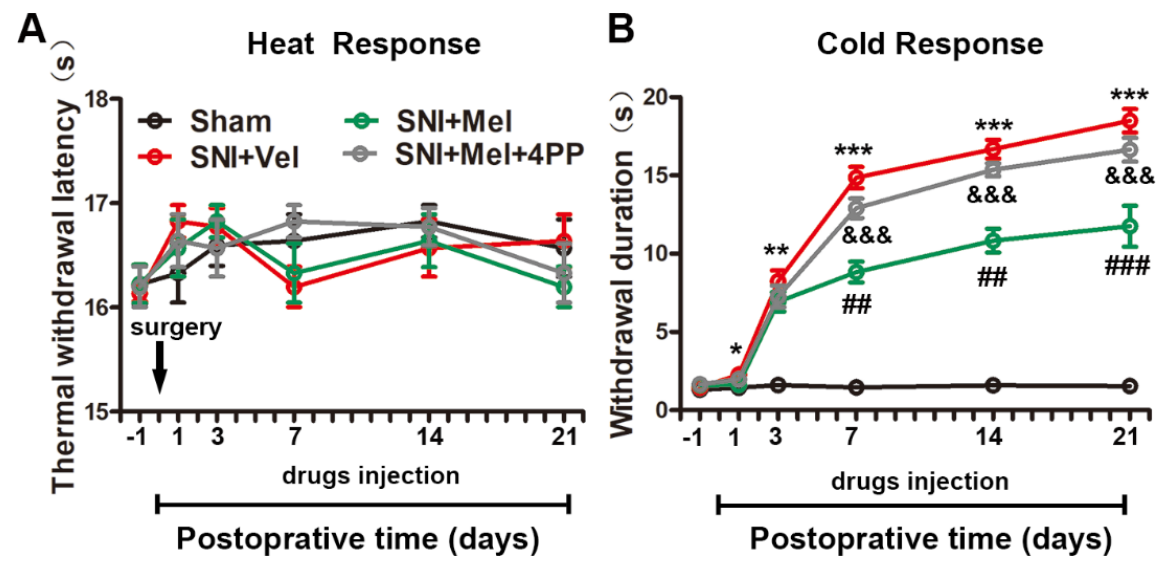

Figure 1. Nociceptive pain related behavioral changes before and after melatonin injections in each group. (A) TWL of rats in response to heat in each group. (B) Time with the paw lifted for rats in response to cold in each group. SNI + Vel group vs. Sham group, $\mathrm{P}<0.001$ $\left({ }^{*} \mathrm{P}<0.05,{ }^{* *} \mathrm{P}<0.01,{ }^{* * *} \mathrm{P}<0.001\right.$ are $1,3,7,14$, and 21 days after surgery $)$, SNI + Mel group vs. SNI + Vel group, $\mathrm{P}<0.005$ (\#\# $\mathrm{P}<0.01$, \#\#\# $\mathrm{P}<0.001$ are 7,14 , and 21 days after surgery; $\mathrm{n}=9$ ). $\mathrm{SNI}+\mathrm{Mel}+4 \mathrm{PP}$ group vs. $\mathrm{SNI}+\mathrm{Mel}$ group, $\mathrm{P}<0.05$ ( $\& \& \& \mathrm{P}<0.001$ are 7,14 , and 21 days after surgery). $\mathrm{n}=9$ for each group. SNI: spared nerve injury, Vel: Vehicle, Mel: Melatonin, TWL: thermal withdrawal latency.

Figure 2 .
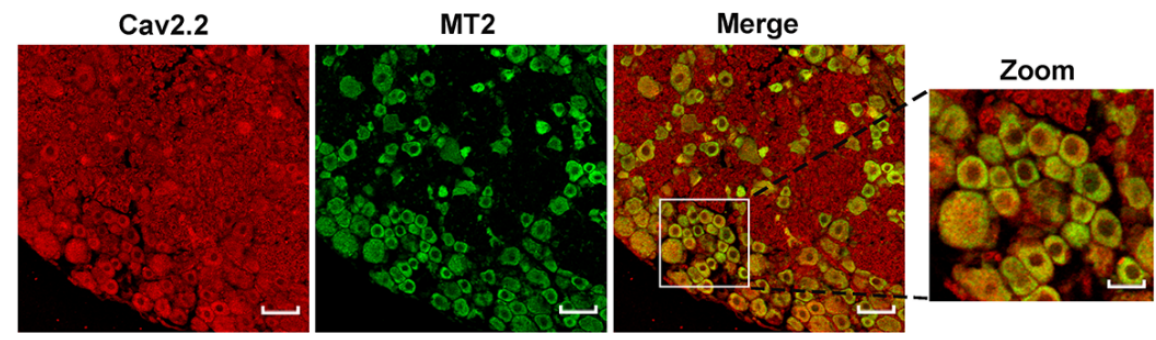

Figure 2. Co-expression of MT2 and Cav2.2 in $\mathbf{L}_{4}-\mathbf{L}_{6}$ DRG neurons . Cav2.2 (red), MT2 (green), Merge (yellow). Scale bar $=50 \mu \mathrm{m}$. Zoom: magnified view of the area within the white square in the Merge panel, Scale bar $=20 \mu \mathrm{m}$.

Figure 3 . 
A

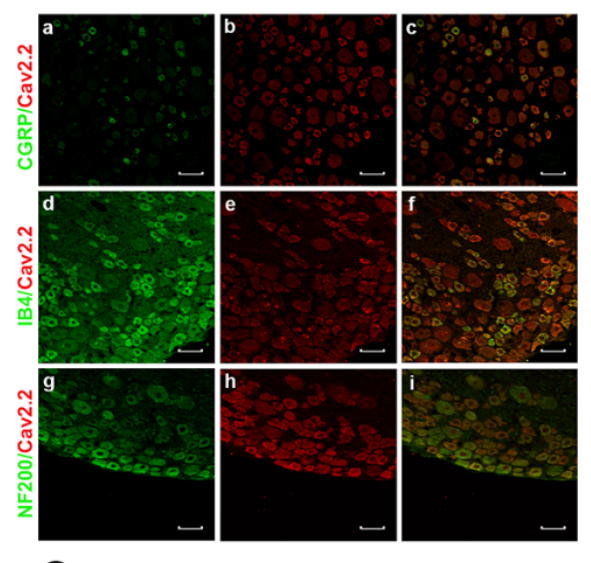

C

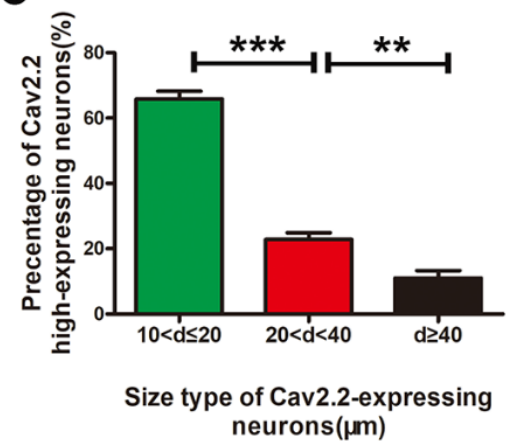

B

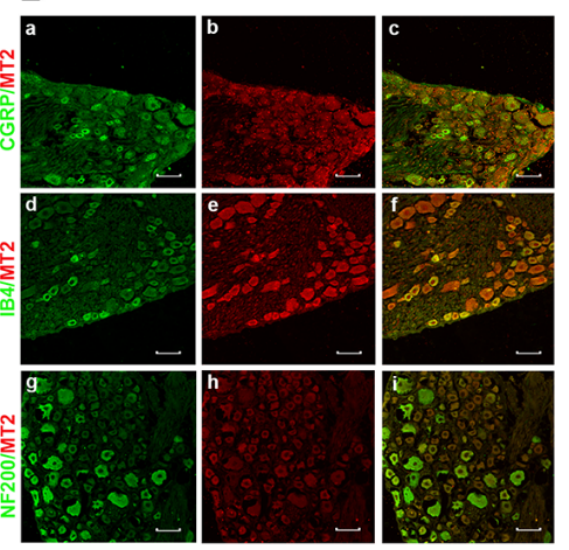

D

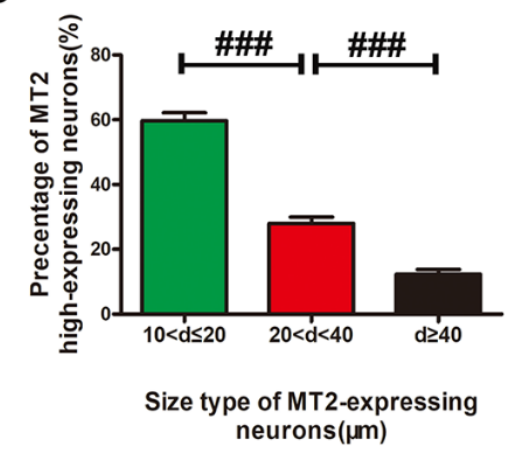

Figure 3. Co-expression of Cav2.2 and MT2 with NF-200, CGRP, and IB4 in $\mathrm{L}_{4}-\mathrm{L}_{6}$ DRG neurons . (A) Representative images showing double immunofluorescence staining of Cav2.2 with NF-200, CGRP, and IB4 in DRG neurons. (B) Representative images showing double immunofluorescence staining of MT2 with NF-200, CGRP, and IB4 in DRG neurons. ( $\mathrm{n}=9$ and scale bar=50 $\mu \mathrm{m}$ for each group). (C) Histograms representing the co-localization data of Cav2.2 with CGRP, IB4, and NF200 in $\mathrm{L}_{4}-\mathrm{L}_{6}$ DRG neurons of diameter $20-40 \mu \mathrm{m}$ vs. $10-20 \mu \mathrm{m} .{ }^{* * *} \mathrm{P}<0.001,{ }^{* *} \mathrm{P}<0.01$ vs. cells with diameter greater than 40 $\mu \mathrm{m}$ ( $\mathrm{n}=9$ for each group). (D) Histograms representing the co-localization data of MT2 with CGRP, IB4,

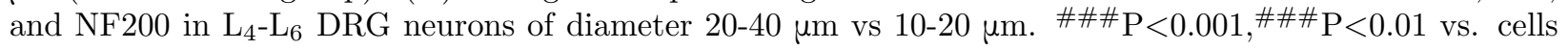
with diameter greater than $40 \mu \mathrm{m}$ ( $\mathrm{n}=9$ for each group). The data were analyzed using one-way ANOVA followed by Tukey's post hoc test.

Figure 4. 
A

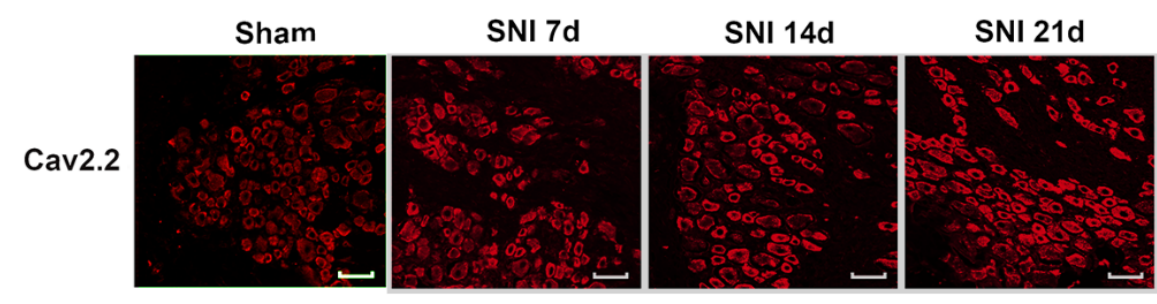

B

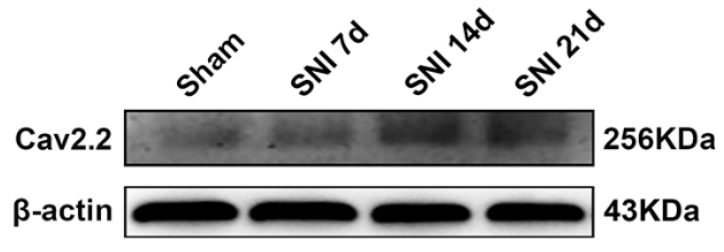

C
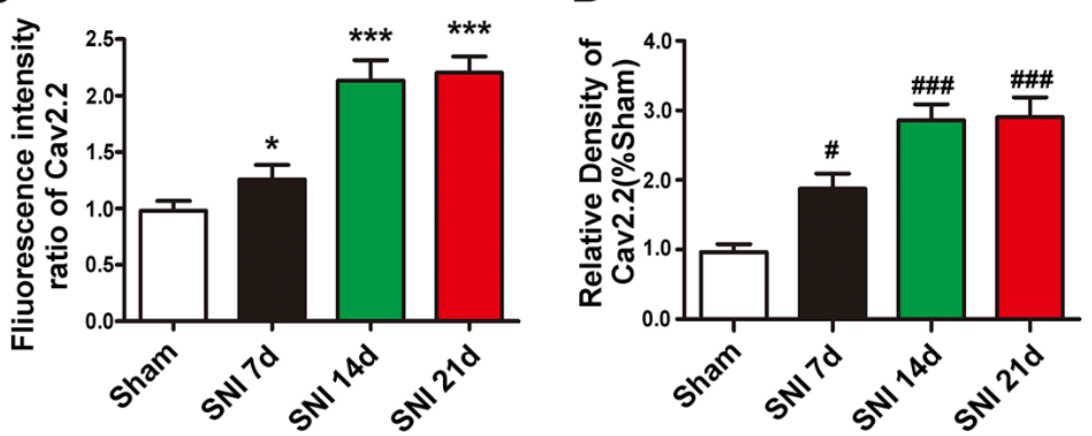

Figure 4. Cav2.2 expression levels in $\mathbf{L}_{4}-\mathbf{L}_{6}$ DRG neurons after SNI surgery . (A) Immunofluorescent intensity representing Cav2.2 in Sham group and 7, 14, and 21 days after SNI surgery groups. (B) Protein expression levels of Cav2.2 in each group. (C) Fluorescence intensity ratio of Cav2.2 in each group. ${ }^{*} \mathrm{P}<0.05,{ }^{* * *} \mathrm{P}<0.001$ vs. Sham group ( $\mathrm{n}=9$ for each group). (D) Relative density of Cav2.2 in each group. $\# \# \mathrm{P}<0.01, \# \# \# \mathrm{P}<0.001$ vs. Sham group ( $\mathrm{n}=9$ for each group). SNI: spared nerve injury, DRG: dorsal root ganglion

Figure 5 . 
A

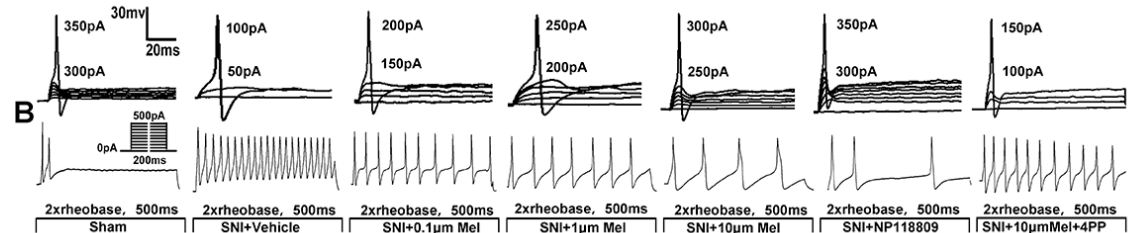

C

D

E

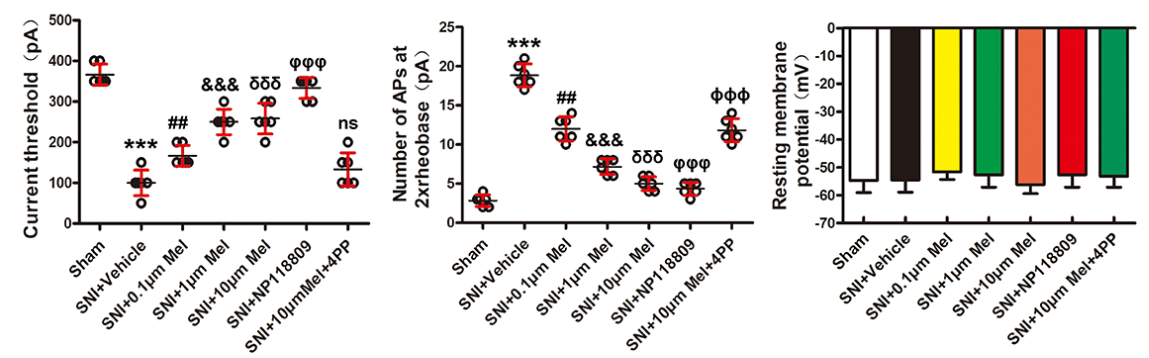

Figure 5. Effect of melatonin on action potential threshold and number in DRG neurons.

Hyperexcitability of $\mathrm{L}_{4}-\mathrm{L}_{6}$ DRG neurons in rats after SNI surgery and effect of different concentrations of melatonin on cell excitability. (B) Number of action potentials at $2 \times$ rheobase in each group. (C) Current thresholds in each group, ${ }^{* * *} \mathrm{P}<0.001$ Sham vs. SNI + Vehicle, ${ }^{\# \# \# P<0.001 ~ S N I+0.1 \mu M ~ M e l ~ v s . ~ S N I ~}+$ Vehicle, and ${ }^{\& \& \&} \mathrm{P}<0.001 \mathrm{SNI}+1 \mu \mathrm{M}$ Mel vs. SNI + Vehicle, ${ }^{\delta \delta \delta} \mathrm{P}<0.001 \mathrm{SNI}+10 \mu \mathrm{M} \mathrm{Mel}$ vs. SNI + Vehicle, ${ }^{\varphi \varphi \varphi} \mathrm{P}<0.001$ SNI+NP118809 vs. SNI + Vehicle. $\mathrm{P}<0.001$ SNI+10 $\mu \mathrm{M}$ Mel+4PP vs. Sham, but $\mathrm{P}=0.1449$ vs. SNI + Vehicle. (D) Number of action potentials at $2 \times$ rheobase in each group, ${ }^{* * *} \mathrm{P}<0.001$ Sham vs. SNI + Vehicle, SNI + Vehicle group vs. SNI+0.1 $\mu \mathrm{M}$ Mel group, \#\# P <0.05, vs. SNI+1 $\mu \mathrm{M}$ Mel group, ${ }^{\& \& \&} \mathrm{P}<0.001$, vs. SNI $+10 \mu \mathrm{M}$ Mel group,${ }^{\delta \delta \delta} \mathrm{P}<0.001$, vs. SNI+NP118809 group, ${ }^{\varphi \varphi \varphi} \mathrm{P}<0.001$, vs. $\mathrm{SNI}+10 \mu \mathrm{M} \mathrm{Mel}+4 \mathrm{PP}$ group, ${ }^{\mathrm{FFF}} \mathrm{P}<0.001$. (E) Resting membrane potential data. Patch clamp data were analyzed using one-way ANOVA followed by Tukey's post hoc test. $\mathrm{n}=6$ neurons in every group. Mel: melatonin. 4PP: 4-P-PDOT (MT2 receptor blocker).

Figure 6 . 
A

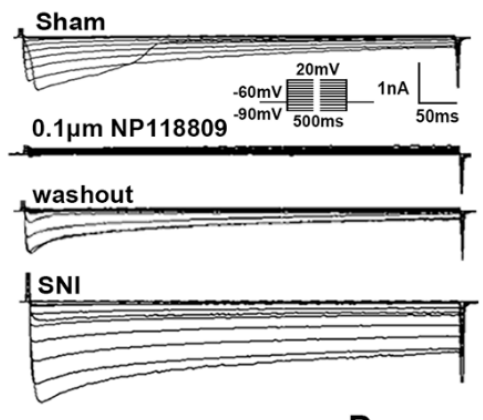

C

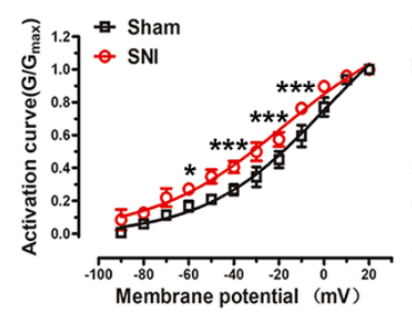

D

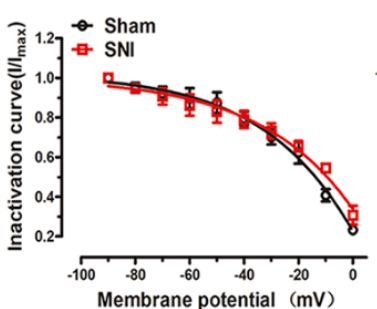

B
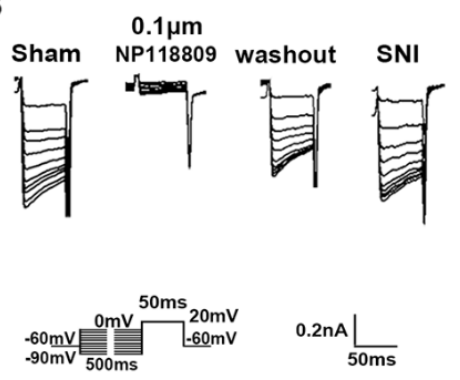

E

$$
\text { Voltage }(\mathrm{mV})
$$

$-100-90-80-70-60-50-40-30-20-10]^{20} 102030$
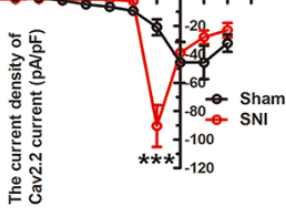

Figure 6. Upregulation of the Cav2.2 N-type calcium currents in $\mathrm{L}_{4}-\mathrm{L}_{6}$ DRG neurons in SNI rats. (A) and (B) The activation and inactivation of N-type calcium currents in $\mathrm{L}_{4}-\mathrm{L}_{6}$ DRG neurons after SNI surgery (Sham group and SNI group). We used a specific N-type calcium channel blocker (0.1 $\mu$ M NP118809), and traces were also obtained after the extracellular fluid washed the neurons for $30 \mathrm{sec}$ (washout). (C) The activation curve significantly shifted to the left of N-type calcium currents, ${ }^{*} \mathrm{P}<0.05,{ }^{* * *} \mathrm{P}<0.001$, SNI group vs. Sham group. (D) However, the inactivation curve showed no different between SNI group and Sham group. (E) Current density of Cav2.2 current in each group. ${ }^{* * *} \mathrm{P}<0.001$, SNI group vs. Sham group. Black trace: Sham group. Red trace: SNI group, $\mathrm{n}=9$ for each group. Patch clamp data were analyzed using one-way ANOVA followed by Tukey's post hoc test, and Boltzmann method was used to the fit I-V and G-V curves.

Figure 7 . 
A

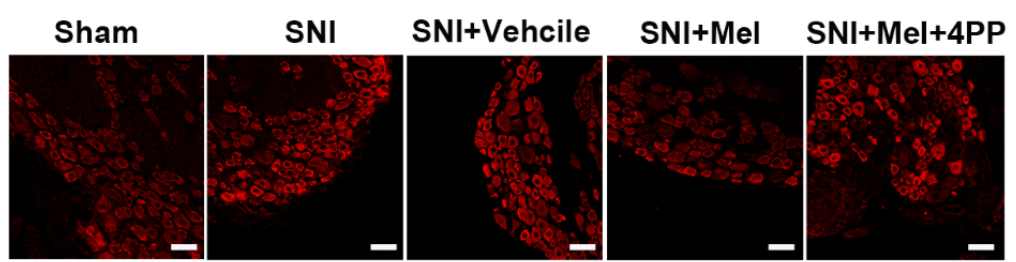

B
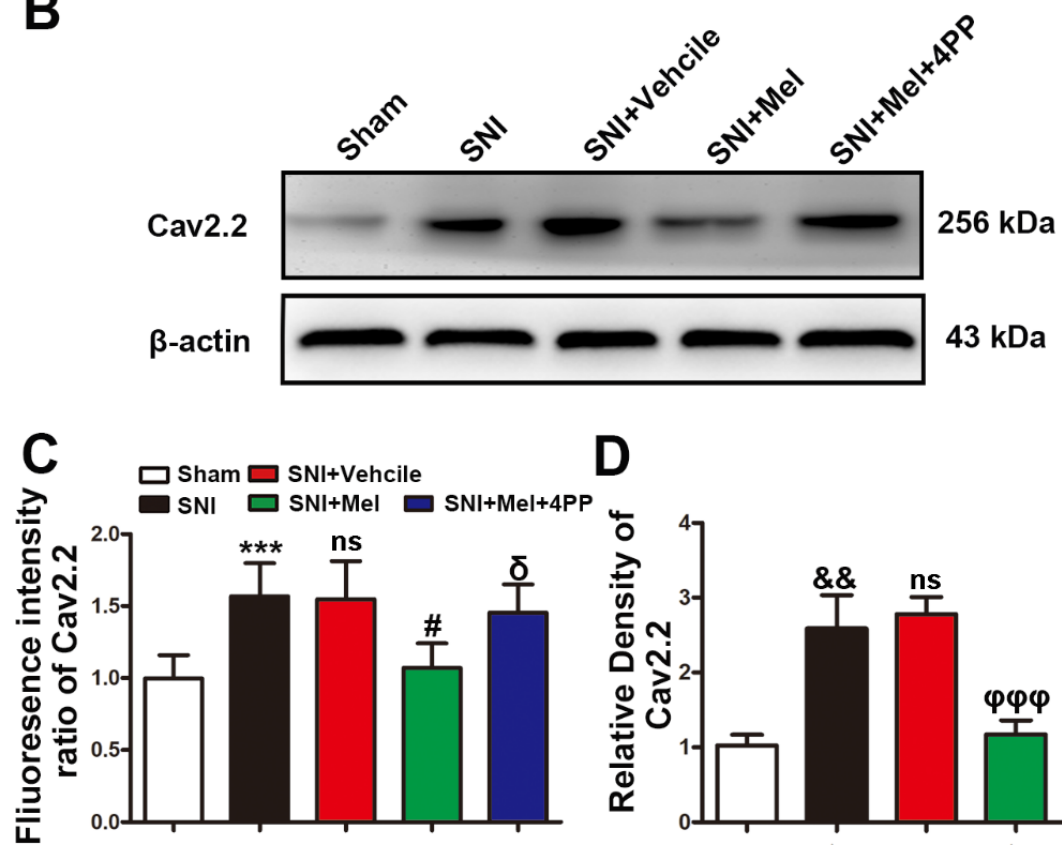

D

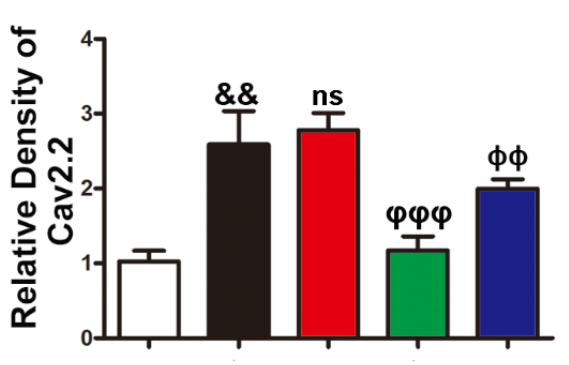

Figure 7. Changes of Cav2.2 expression in DRG neurons after SNI surgery and melatonininjections . (A) Immunofluorescence expression of Cav2.2 in each group. (B) Expression levels of Cav2.2 and $\beta$-actin in each group. (C) Fluorescence intensity ratio (left) and relative density of Cav2.2 (right) in each group. Difference between SNI + Vel group vs. SNI group is not significant. ${ }^{\#} \mathrm{P}<0.01,{ }^{* *} \mathrm{P}<0.01 \mathrm{SNI}+\mathrm{Mel}$ group vs. SNI + Vel group, $\mathrm{n}=9$ for each group. Vel: Vehicle, Mel: melatonin. ns:nostatisticalsignificance . 


\section{A}

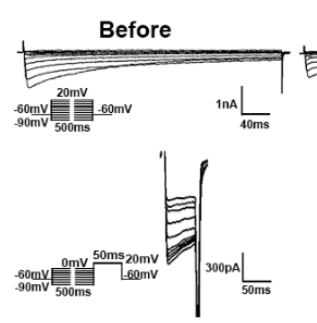

B

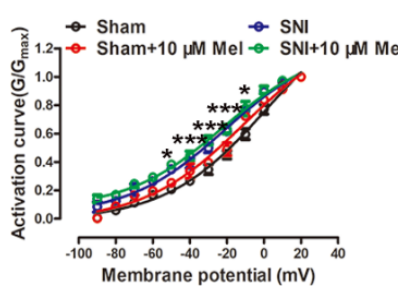

C
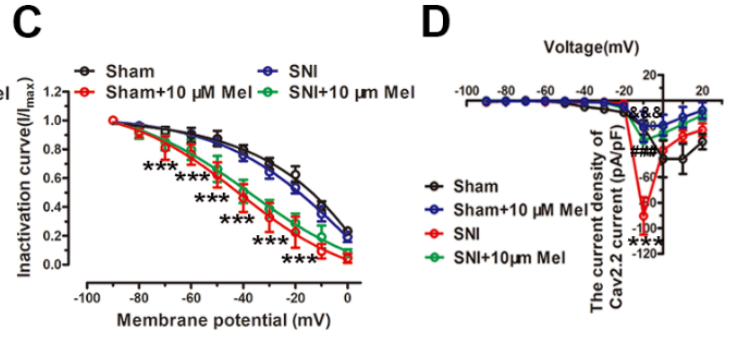

Figure 8.

Figure 8. Effect of melatonin on voltage-dependence of activation and inactivation of Cav2.2 channels in DRG neurons of rats after SNI surgery . (A) Representative traces showing the current of DRG neurons after a step protocol of activation traces (up) and inactivation traces (down). Before: Traces obtained before melatonin was used in SNI group. $10 \mu \mathrm{M}$ Mel: $10 \mu \mathrm{M}$ melatonin was used. Net Current: Traces obtained by subtracting the traces of $10 \mu \mathrm{M}$ Mel from the traces of Before. Washout: Extracellular fluid was used to washed DRG neurons. (B) and (C) Activation and inactivation curves. Black trace: SNI+ Vel group before melatonin was used. Red trace: SNI $+10 \mu \mathrm{M}$ Mel group trace after perfusing the $10 \mu \mathrm{M}$ melatonin. Sham $+10 \mu \mathrm{M} \mathrm{Mel} \mathrm{group} \mathrm{vs.} \mathrm{Sham} \mathrm{group,} \mathrm{P}<0.001$ (Not marked in the figure) and SNI $+10 \mu \mathrm{M}$ Mel group vs. SNI group, ${ }^{* * *} \mathrm{P}<0.001$. (D) Current density of Cav2.2 current in each group. SNI+Vel group vs. Sham group, ${ }^{\# \#} \mathrm{P}<0.001$ and SNI $+10 \mu \mathrm{M}$ Mel group vs. SNI+Vehicle group, ${ }^{\&} \& \& \mathrm{P}<0.001 . \mathrm{n}=7$ for SNI+ Vel group and SNI group, $\mathrm{n}=9$ for SNI $+10 \mu \mathrm{M}$ Mel group. Patch clamp data were analyzed using one-way ANOVA followed by Tukey's post hoc test. Boltzmann method was used to fit I-V and G-V curves. Vel: vehicle. Mel: melatonin.

Figure 9. 


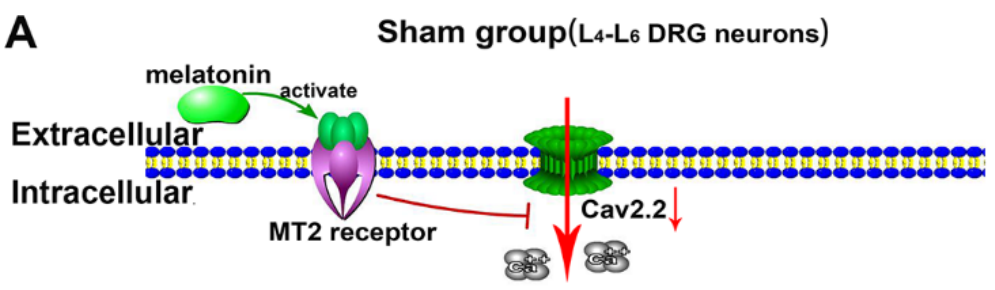

1. Melatonin reduced the current density of Cav2.2 current.

2. Cav2.2 more easier to be inactivated by melatonin.

Nucleus

Weverar

B
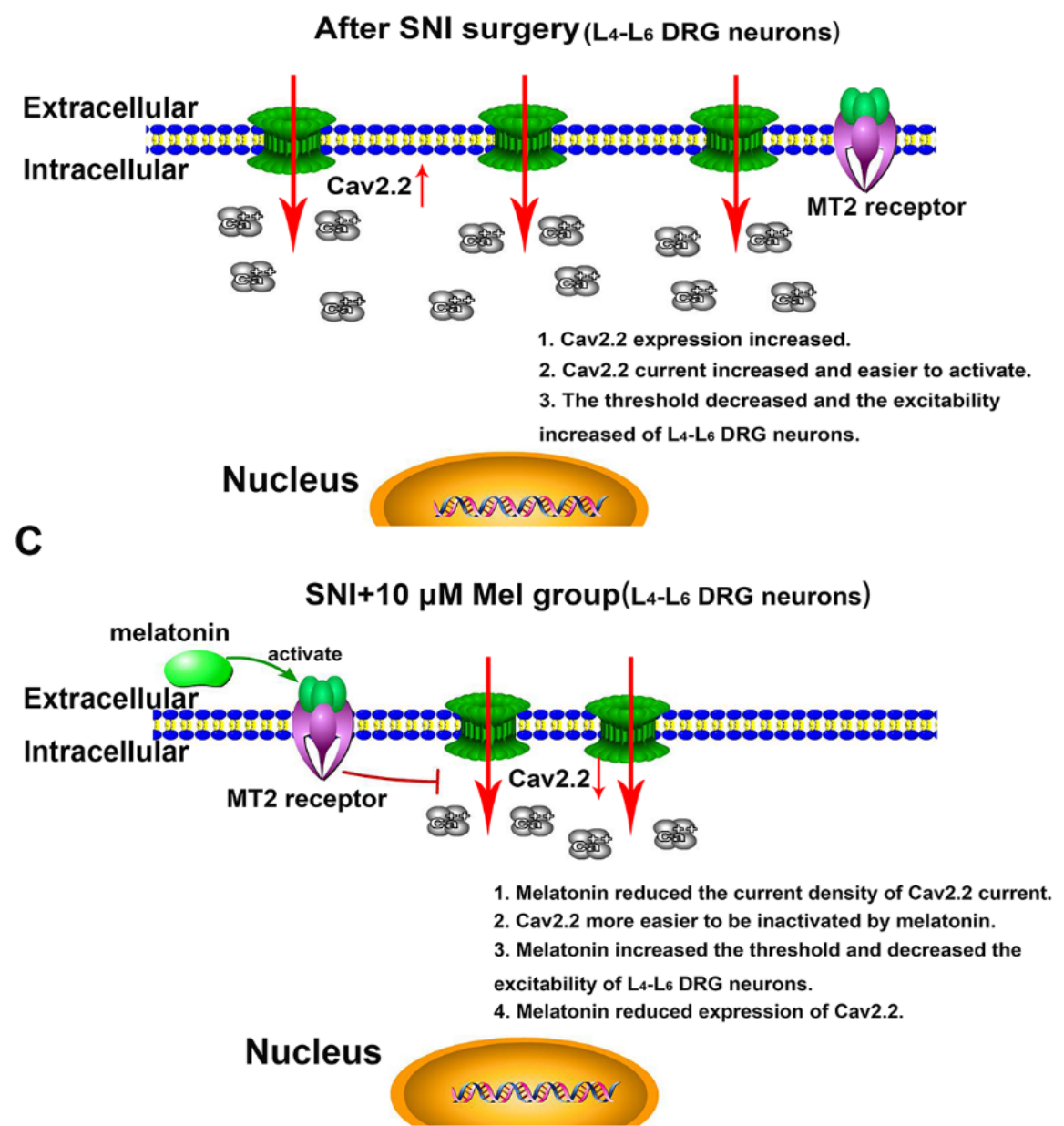

Figure 9. Schematic diagram of the effect of melatonin on Cav2.2 channels in DRG neurons of rats . (A) Melatonin activated MT2 receptors and reduced the Cav2.2 current by accelerating Cav2.2 inactivation. (B) After SNI surgery, the Cav2.2 expression and current increased, and the excitability of DRG neurons also increased. (C) Melatonin reduced the Cav2.2 expression and current and decreased the excitability of DRG neurons. At the same time, Cav2.2 was more easily inactivated by melatonin. 
Supplement Figure

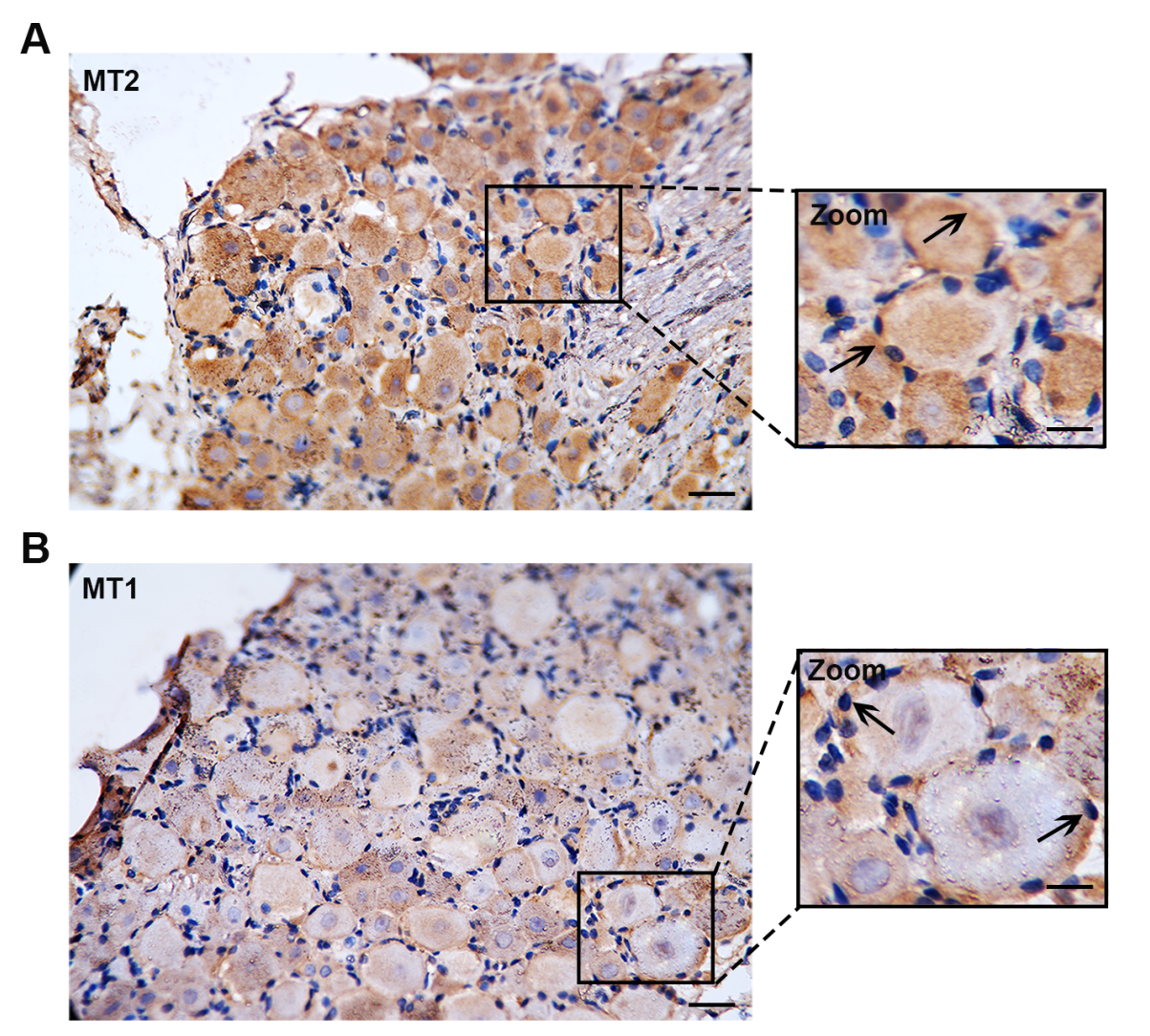

Figure 10. (A and B) DAB staining of MT2 and MT1 in the $\mathrm{L}_{4}-\mathrm{L}_{6}$ DRG in control rats, respectively. The arrows in A represent the MT2-immunoreactive DRG neurons. The arrows in B indicate the MT1-immunoreactive satellite cells. Zoom: magnified view of the area within the black square in the A and B panel (Scale bar=25 $\mu \mathrm{m}$ in A and $20 \mu \mathrm{m}$ in B; Scale bar=10 $\mu \mathrm{m}$ in Zoom.)

\section{Hosted file}

Data-Availability-Statement.docx available at https://authorea.com/users/450963/articles/ 549227-melatonin-inhibits-the-up-regulation-of-n-type-calcium-channel-in-neuropathicpain-by-activating-the-mt2-receptor-in-rats 